\title{
Temporospatial characterization of the bronchus associated lymphoid tissue (BALT) of the one humped camel (Camelus dromedarius)
}

\author{
Omnya Elhussieny ${ }^{1} \cdot$ Mohamed Zidan $^{2}$ \\ Received: 28 October 2020 / Accepted: 29 March 2021 / Published online: 17 April 2021 \\ (C) The Author(s), under exclusive licence to Springer Nature B.V. 2021
}

\begin{abstract}
Background Bronchial-associated lymphoid tissue (BALT) is responsible for the local immune response of the lung against airborne infections. The structure of this tissue varies according to species and age.

Aim The aim of this study was to describe the possible age-related structural variation of the BALT of the one humped camel. Material and methods Fresh specimens from both lungs of 15 clinically healthy male camels ( 10 months-12 years) were studied with light and electron microscopes.

Results The BALT in the camel was variable from few lymphocytes to well-organized lymphoid tissue with a clear germinal center. The BALT of the bronchi is a constant lymphoid tissue in young and adult camels which may be of the large size with clear germinal center in response to repeated immune reaction and involutes in old age. The BALT of the bronchioles may be induced and develops mainly due to an immune reaction and showed great morphological variations and observed in different ages. High endothelial venules were associated with BALT in the bronchi but not with that of the bronchioles. The BALTassociated epithelium was tall pseudostratified columnar ciliated epithelium with goblet cells in the extrapulmonary bronchi changed to pseudostratified columnar ciliated epithelium mucous secreting cells in the intrapulmonary bronchi and simple columnar ciliated to simple cuboidal epithelium with Clara cells without goblet cells or mucous secreting cells in the bronchioles. Conclusions The BALT of the bronchi is a constant lymphoid tissue in young and adult camels and involutes in old age. The BALT of the bronchioles may be induced and develops mainly due to an immune reaction and observed in different ages.
\end{abstract}

Keywords Camel $\cdot$ Lung $\cdot$ BALT $\cdot$ Bronchi $\cdot$ Bronchioles

\section{Introduction}

The outbreak of novel SARS-CoV-2 coronavirus that emerged in the city of Wuhan, China, on 31 December 2019 caused a worldwide COVID-19 fatal outbreak affecting human respiratory system with a possible zoonotic origin of the

This article belongs to the Topical Collection: Camelids Guest Editor: Bernard Faye

Mohamed Zidan

Mohamedzidan@alexu.edu.eg; mzidan0@gmail.com

Omnya Elhussieny

Omnya.evet@gmail.com; omnya.elhussieny@mau.edu.eg

1 Department of Histology and Cytology, Faculty of Veterinary Medicine, Fuka, Matrouh University, Matrouh 51744, Egypt

2 Department of Histology and Cytology, Faculty of Veterinary Medicine, Alexandria University, Alexandria 21944, Egypt virus (Mackenzie and Smith 2020). Compared to the severe course of MERSCoV infections in humans, camels show only mild and transient respiratory symptoms (Hussen and Schuberth 2021). This develops the need of knowing the localized immune structure associated with the respiratory system of all species. The outbreak of severe illness began in 2012 in Saudi Arabia with the Middle East Respiratory Syndrome (MERS), where one humped camels were the most probable zoonotic source of this respiratory syndrome caused by coronavirus (MERS-COV) causing high case-fatality rate too. Failure of controlling the zoonotic sources of this disease, dromedary camels, leads to the continuous epidemic of MERS-COV in the Middle East (Zhou et al. 2015). The mucosal surface of the respiratory tract is permanently in direct contact with various antigens present in the external environment including pathogenic microbes (bacteria, viruses, parasites) and innocuous materials such as dust and proteins of plant and animal origins. The lung immune system can deal 
with all of these threats through a variety of specific mechanisms; one of them is the bronchus-associated lymphoid tissue (BALT) (Holt et al. 2008). BALT is a constitutive mucosal lymphoid tissue adjacent to major airway in some mammalian species, including camel (Elhussieny et al. 2017), cattle (Anderson et al. 1986), human and occasionally mice (Holt et al. 2008), rats, and rabbits (Randall 2010) and absent in dogs and cats (Pabst and Gehrke 1990; Bienenstock and McDermott 2005). BALT is exposed to antigens from the airways and initiates local immune responses and maintains memory cells in the lungs (Randall 2010). BALT is made up of a population of lymphocytes beneath a specialized epithelium with distinct age-related differences in its structure (Fagerland and Arp 1990, 1993). The BALT of the one humped camel is composed of aggregated lymphoid patches of variable sizes along the bronchial tree under the epithelial surface in the lamina propria, submucosa, and also in the adventitia. High endothelial venules were present at its periphery (Elhussieny et al. 2017). BALT might play a critical role in antigen recognition, initiation of immune response, and dissemination of primed lymphoid cells in the respiratory tract (Pabst and Gehrke 1990). BALT is an entry site for antigens or vaccines which is essential for applying a successful mucosal vaccination through trachea in human, particularly for infectious diseases affecting the lung (Pabst and Tschernig 2010). Several studies described the peculiar structures of the immune organs of the dromedary camel in different age without considering the BALT (Zidan et al. 2000a, b; Zidan and Pabst 2002, 2012). In spite of that, the basic structure of the BALT of the one humped camel was describe before (Elhussieny et al. 2017) and recently that of Bactrian camel (He et al. 2019). There is no any available data about the age-related morphological changes of camel BALT. Therefore, the present study aimed to investigate age-related structural changes of the BALT of the dromedary camel; this might help in comparative studies and assist in adjusting an aerosol vaccination program to control airborne infection affecting camels in different ages; all of this may protect human from camel-borne zoonotic diseases as MERS-COV, brucellosis, Rift Valley fever, Yersinia pestis, Coxiella burnetii, and CrimeanCongo hemorrhagic fever (Zhu et al. 2019) and prevent respiratory infectious diseases in this species.

\section{Materials and methods}

\section{Samples}

The present study was done on 15 clinically healthy male camels their ages ranged from 10 months to 12 years. These animals were slaughtered for human consumption according to the rules of the Egyptian Veterinary Authorities in the abattoir of Marsa Matrouh, Matrouh, Egypt, or Koom Hamada,
Elbehera, Egypt. Fresh specimens were taken from both lungs. The animals were selected from 5 age groups. Each group included 3 animals: group A: 10 months camels; group B: 18 months camels; group C: $3-4$ years camels; group D: 67 years camels; and group E: 12 years camels. Fresh specimens were obtained from each lung of all animals including extrapulmonary bronchi, large intrapulmonary bronchi with lung tissue, small intrapulmonary bronchi and lung tissue, and lung tissues contain bronchioles. The samples were prepared for histological and ultrastructural examination as follow:

\section{Light microscopy}

The specimens were fixed in $10 \%$ phosphate-buffered formaldehyde. The fixed specimens were processed for paraffin sectioning. Serial sections $(5 \mu \mathrm{m})$ were prepared as outlined by Wolfe 2019 and stained using the following stains as outlined by Bancroft and Layton (2019) and Layton and Bancroft (2019): Mayer's hematoxylin and eosin (H\&E), Van Gieson's stain, Gomori's trichrome stain, Gordon and Sweet's stain, and Combined Alcian blue-PAS stain.

\section{Transmission electron microscopy:}

Fresh specimens, about $1 \mathrm{~mm}^{3}$ in size, were obtained from the epithelium with the underlying lamina propria and submucosa of the bronchi and lung tissue with the bronchioles were immediately fixed in $4 \mathrm{~F} 1 \mathrm{G}$ ( $2 \%$ formaldehyde, $1.25 \%$ gluteraldehyde in $0.1 \mathrm{M}$ sodium cacodylate, $\mathrm{PH}$ 7.2) and stored at $4^{\circ} \mathrm{C}$. Depending on histological finding, the specimens of the 4 years camels (the camels with well-developed BALT) were processed as outlined by Woods and Stirling (2019). For details, see Zidan and Pabst (2009). Semithin sections $(1 \mu \mathrm{m})$ were stained with toluidine blue and examined with the light microscope. Suitable areas for the electron microscopic examination were determined. Ultrathin sections $(60-100 \mathrm{~nm})$ were stained with uranyl acetate followed by lead citrate. The sections were examined with $100 \mathrm{CX}$ JEOL transmission electron microscope working at $80 \mathrm{KVs}$

\section{Results}

\section{BALT of the extrapulmonary bronchi}

The extrapulmonary bronchi of the camel were very short canal connecting the trachea with the intrapulmonary bronchial tree. Each extrapulmonary bronchus was lined with tall pseudostratified columnar ciliated epithelium with goblet cells. The BALT was rarely seen in young age camels of 10-18 months. If present, the BALT was in the form of few diffusely distributed lymphocytes specially in the superficial 

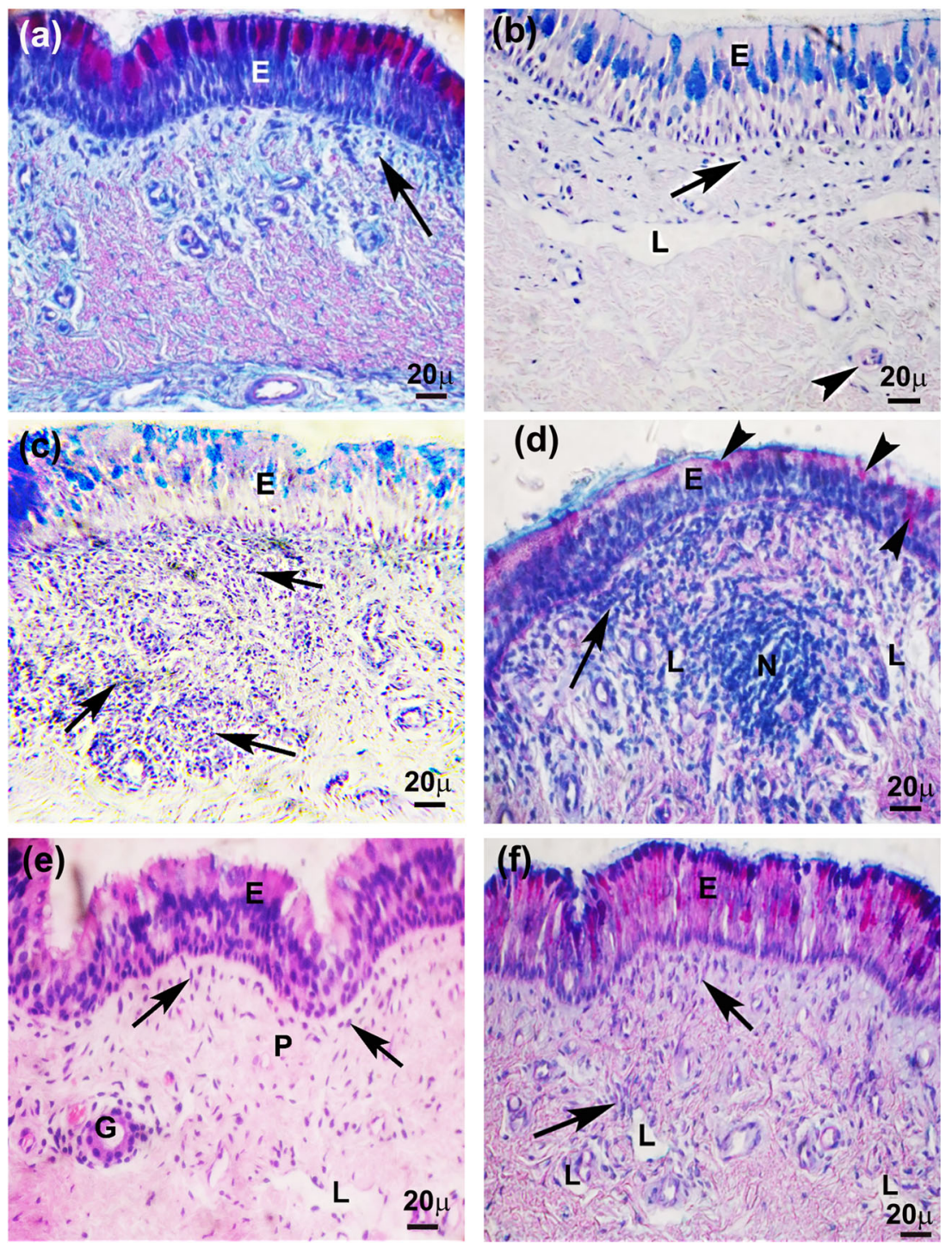

Fig. 1 Camel extrapulmonary bronchi. (a) At 10 months, BALT is formed of few diffused lymphocytes (arrow) in the lamina propria. The associated epithelium (E) is pseudostratified tall columnar ciliated with acid (blue) interdigitating with neutral (magenta) mucin-secreting goblet cells. Alcian blue-PAS. (b) At 18 months, BALT is formed of few diffused lymphocytes (arrow). The associated epithelium (E) is pseudostratified tall columnar epithelium with acid mucin (blue) secreting goblet cells. L, lymphatic vessel. Arrowhead, HEV. Alcian blue-PAS. (c) At 3 years, BALT has diffused lymphocytes (arrows). The associated epithelium (E) is formed of pseudostratified tall columnar ciliated cells with acid mucin secreting cells. Alcian blue-PAS. (d) At 7 years, BALT is

part of the lamina propria adjacent to the epithelial surface (Fig. 1a and b); the associated epithelium was tall pseudostratified columnar ciliated epithelium with goblet cells. A constant structure of lymphoid nodules and/or diffused lymphocytes was observed in the lamina propria of middle age group of 3-4 and 6-7 years (Fig. 1c and d). In the older ages (12 years), the BALT of the extrapulmonary bronchi was rarely observed. If present, it was represented by few diffusely distributed lymphocytes (Fig. 1e and f). The formed of lymphoid nodule $(\mathrm{N})$ and diffused lymphocytes in the lamina propria (arrow). The associated epithelium (E) is pseudostratified columnar ciliated with few neutral mucin secreting cells (arrowheads). L= lymphatic vessels. Alcian blue-PAS. (e) At 12 years, BALT is represented by few diffusely distributed lymphocytes (arrows) in the lamina propria (P). The associated epithelium (E) is pseudostratified tall columnar ciliated cells. $\mathrm{L}=$ lymphatic vessel. $\mathrm{G}=$ bronchial gland. $\mathrm{H} \& \mathrm{E}$. (f) At 12 years, BALT is formed of few diffused lymphocytes (arrows) in the lamina propria. The associated epithelium (E) is pseudostratified tall columnar epithelium rich in acid and neutral mucin-secreting cells. $\mathrm{L}=$ lymphatic vessels. Alcian blue PAS

goblet cells were not recognized in the BALT-associated epithelium of camels of 3-12 years which was replaced with acid mucin secreting cells in the age group of 3-4 years (Fig. 1c) and neutral and acid mucin secreting cells in 6-12 years old camels (Fig. $1 \mathrm{c}$ and f). High endothelial venules and lymphatic vessels were a constant structure associating the BALT of certain age groups studied (Fig. 1b, d, e, and f). The high endothelial venules and lymphatics were prominent in the middle age of 3-4 and 6-7 years associated with the 

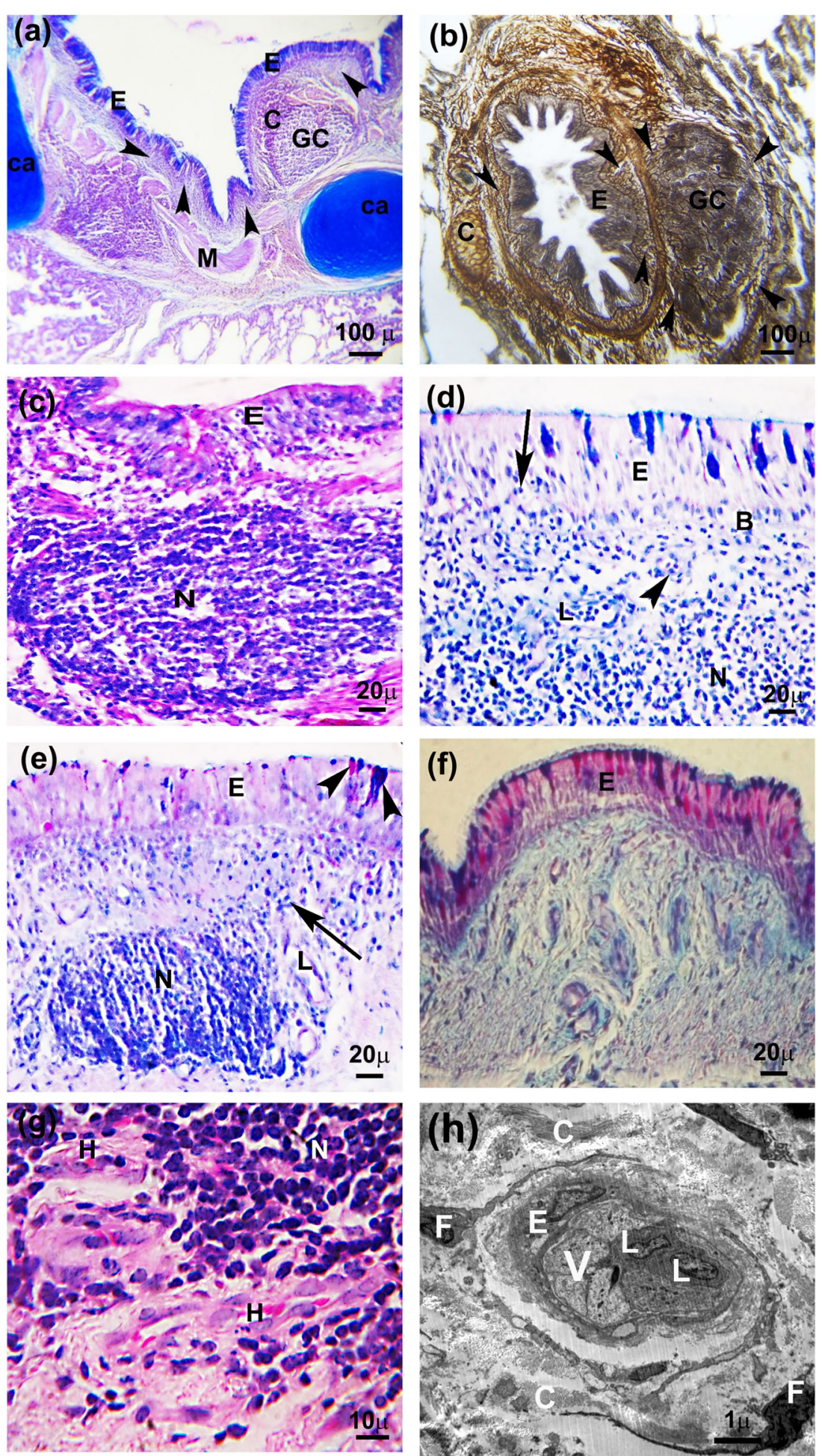

well-developed BALT. In older age camels of 12 years, only lymphatics were observed (Fig. 1e and f).

\section{BALT of the intrapulmonary bronchi}

The BALT of the intrapulmonary bronchi was well organized into prominent lymphoid nodules with clear germinal centers

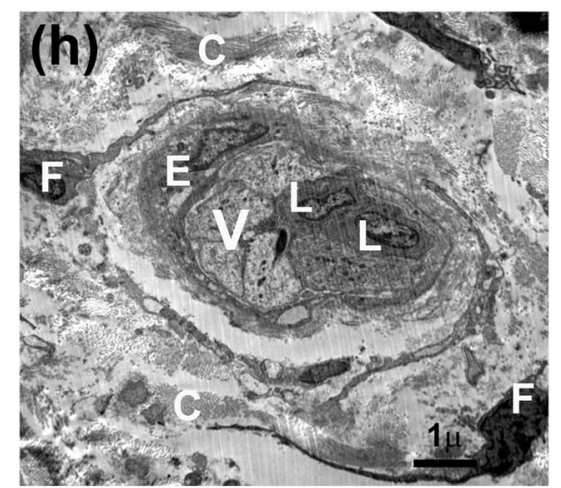

and interfollicular diffused lymphocytes supported with reticular fibers in camels at the age of 10 months (Fig. 2a and b), 18 months (Fig. 2c), 3-4 years (Fig. 2d), and 6-7 years (Fig. 2e). In the older camels of 12 years, no or few diffused lymphocytes were localized only in the lamina propria (Fig. 2f). High endothelial venules of variable number were distributed at the margin of the BALT and between the lymphoid nodules in all 
4 Fig. 2 Camel intrapulmonary bronchi. (a) The BALT at10 months is formed of lymphoid nodule with germinal center (GC), corona (C), and diffused lymphocytes (arrowheads). The associated epithelium (E) is pseudostratified columnar rich in acid mucin-secreting cells. M, smooth muscle, ca, cartilage. Alcian blue-PAS. (b) At 10 months, BALT is supported with reticular fibers (arrowheads) which are spare in the germinal center (GC). E, epithelium. C, cartilage. Gordon and Sweet's reticulin. (c) a prominent BALT at 18 months $(\mathrm{N})$. The associated epithelium (E) is pseudostratified columnar neutral mucous secreting epithelium infiltrated with lymphocytes. Alcian blue-PAS stain. (d) The BALT at 4 years is well developed (N). The associated epithelium (E) is pseudostratified columnar with acid mucin and few neutral mucin-secreting cells. Alcian blue-PAS. (e) At 7 years, BALT is formed of lymphoid nodule (N) and diffused lymphocytes (arrow). The associated epithelium (E) contains few acid (blue) and neutral (magenta) mucin-secreting cells. L= lymphatic vessel. Alcian blue-PAS. (f) At 12 years, BALT is formed of few lymphocytes in the lamina propria. The epithelium (E) is pseudostratified columnar ciliated with acid (blue) and dominating neutral (magenta) mucin-secreting cells. Alcian blue-PAS. (g) HEVs (H) are present at the margin of the BALT (N) of 7 years' camel. H\&E. (h) High endothelial venule of 4 years camel with endothelial lining (E) and migrating lymphocytes (L). F, fibrocytes. C, collagen fibers

age group except the oldest group of 12 years. The number of these venules was related to the size of the BALT. Variable number of migrating lymphocytes was observed in the wall of these venules (Fig. $2 \mathrm{~g}$ and h). Lymphatic vessels of variable sizes were extended at the margin of the BALT of different ages (Fig. $2 \mathrm{~d}$ and e). These lymphatics were present even if the BALT was formed from few lymphocytic aggregations at the age of 12 years. The BALT-associated epithelium of the intrapulmonary bronchi of different ages is formed from pseudostratified columnar ciliated epithelium mucous secreting cells resting on a basement membrane. No goblet cells were observed in general. In the age group of 10 months, the columnar cells possessed acid mucin in their apical cytoplasm (Fig. 2a). Neutral mucin secreting cells increased gradually on the expense of acid mucin secreting cells with age starting from the age of 18 months (Fig. 2c) and became mostly neutral mucous secreting columnar cells in 12 years old camels (Fig. 2f). Ultrastructure of the BALT-associated epithelium revealed that these cells produce characteristic bipartite mucous secretory granules of low and high electron dense parts. The ordinary low dense portion of the granule was predominating (Fig. $3 \mathrm{a}$ and b). In the same time, variable numbers of lymphocytes were infiltrating the BALTassociated epithelium of camels of 10 months to 7 years (Fig. 3c-e). This infiltration ranged from few lymphocytic infiltrations to heavy infiltration. In the camels of 12 years, no lymphocytic infiltration was observed in the associated epithelium (Fig. 3f).

\section{BALT of the bronchioles}

The bronchioles were the narrowest part of the bronchial tree with the thinnest wall. The surface epithelium was simple columnar ciliated epithelium to cuboidal epithelium. In the bronchioles, the BALT was a consistent structure in different age group of the animal studied with minor morphological variation. It was formed from diffused lymphocytes to wellorganized structure of small lymphoid nodule and diffused lymphocytes (Figs. 4a-c). The BALT was localized in the lamina propria, submucosa, and adventitia of the bronchioles. In general, no high endothelial venules or lymphatic vessels were observed in association with the BALT of the bronchioles. The BALT of the bronchioles of different ages was supported with reticular fiber network (Fig. 4d). The BALTassociated epithelium was simple columnar ciliated to simple cuboidal epithelium with Clara cells. No goblet cells or mucous secreting cells were observed. Few interepithelial lymphocytic infiltrations were seen (Fig. $4 a-c)$.

\section{Discussion}

The present study, to the best of our knowledge, is the first work describes the age-related morphological changes of the BALT in the one humped camel (Camelus dromedarius). The BALT is a distinct lymphoid compartment associated with bronchi and bronchioles involved in sampling of antigens entering the lung and initiation of the immune response against them (Bienenstock and Befus 1984). The investigation of bronchi and bronchioles of the camels of different ages revealed that the BALT of variable shapes, sizes, and location was regularly present in all specimens of certain age group studied with some age-related peculiarities. The presence of this local BALT in the lung of the camel may have major role in initiating immune response against airborne antigens as explained by MoyronQuiroz et al. (2007) who concluded that the local lymphoid tissues are fully capable of initiating primary immune responses, and once local lymphoid tissues are formed, they may initiate primary immune responses to new antigens even faster than conventional lymphoid organs due to their close proximity to antigen. The organization of the BALT was variable in extrapulmonary bronchi, intrapulmonary bronchi, and bronchioles in relation to age. In the extrapulmonary bronchi, the BALT-associated epithelium was pseudostratified tall columnar ciliated epithelium which possessed acid mucin secreting goblet cells in young ages (10-18 months); these goblet cells were not recognized in 3-12 years which was replaced with acid mucin-secreting columnar cells in the age group of 3 4 years and changed to neutral and acid mucin-secreting columnar cells in 6-12 years camels. This variation in the number of goblet cells and the $\mathrm{pH}$ of the mucin may have a physiological or immunological role. Thornton et al. (2008) mentioned that the structural diversity of mucin may be present to cope with diverse and rapidly changing pathogens in the external environment. The same authors concluded that the protective mucus layer coats the nonkeratinized epithelial 
Fig. 3 Camel intrapulmonary bronchi. (a) The BALT-

associated ciliated

pseudostratified epithelial cells

(E) of a 4 years camel contain se-

cretory granules (arrowheads) some of them are bipartite (arrow). Note the electron dense secretory mucous (D). (b) The BALT-associated epithelium of 4 years camel showing several mucous secretory granules (arrowheads) some of them are bipartite (arrows). (c) The BALT at 10 months has a lymphoid nodule with a germinal center (GC) and corona (C) facing the pseudostratified columnar epithelium (E) which is highly infiltrated with lymphocytes. The HEVs (arrows) and lymphatic vessel (L) are present at the margin of BALT. M, smooth muscle. H\&E. (d) The BALT (arrows) of 4 years camel is associated with epithelium (E) rich in infiltrated lymphocytes. Arrowheads, HEVs. $L$ lymphatic vessel. H\&E stain. (e) BALT-associated epithelium of 7 years camel contains interepithelial lymphocytes (arrow) forming lymphoepithelium (E). H\&E. (f) At the age of 12 years, the BALT is formed of few diffused lymphocytes (arrows). The associated epithelium (E) is pseudostratified columnar ciliated epithelium. H\&E stain.
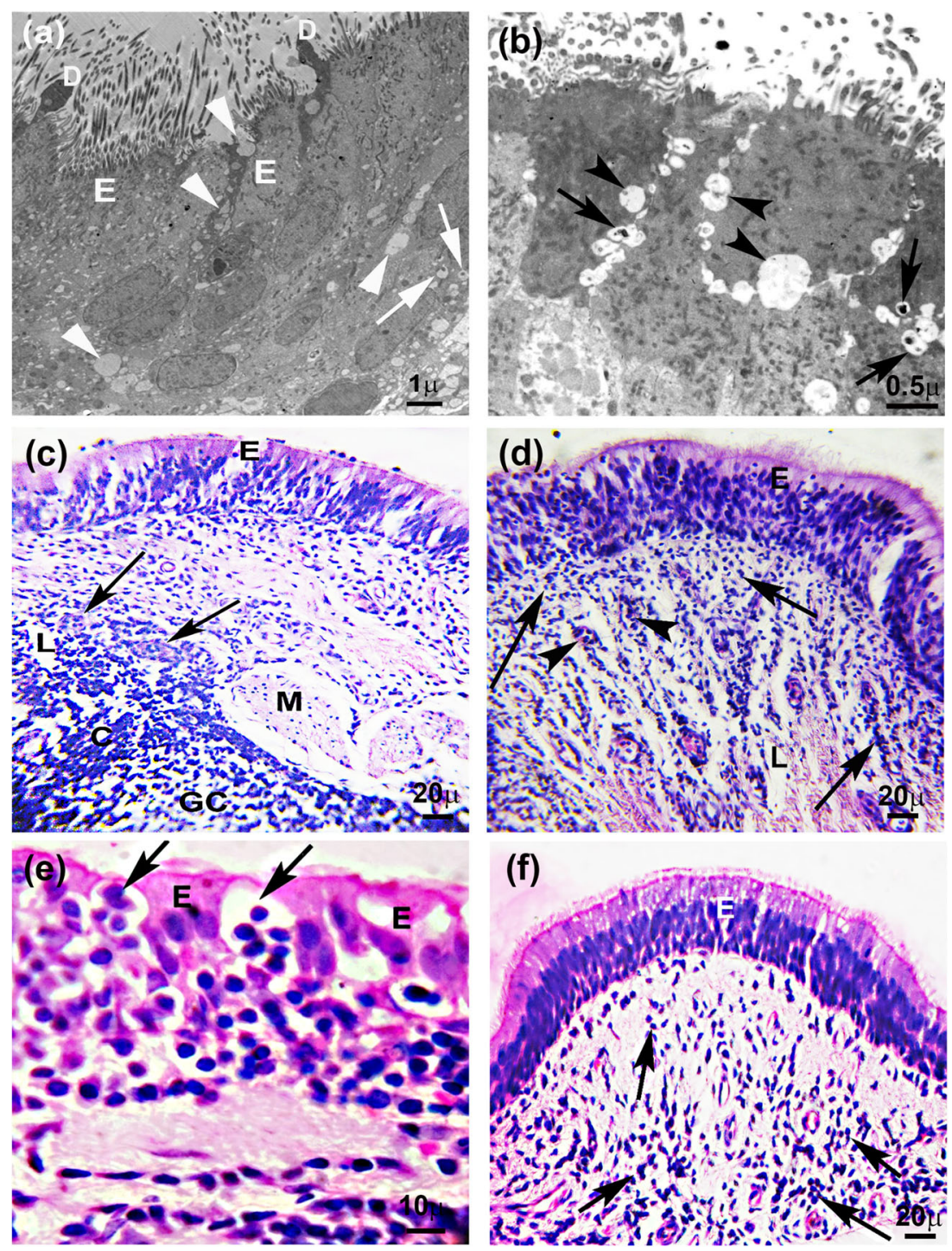

surfaces which are a key component of innate defense against pathogens where the respiratory mucus is rich in molecules involved in host defense from infection, including secretory IgA, collectins, defensins, cathelicidins, and histatins; they explained that there are 17 known gens controlling the formation of different mucins in the body.

The presence of BALT in the extrapulmonary bronchi showed a major age-related variation. It was rarely seen in young age camels of 10-18 months. If present, the BALT was in the form of few diffusely distributed lymphocytes specially in the part of the lamina propria adjacent to the epithelial surface. A constant structure of lymphoid nodules and/or diffused lymphocytes was observed in the lamina propria of the middle age group (3-7 years). Secondary lymphoid nodules with prominent germinal center were common in this age. In the older ages studied in this work (12 years), the BALT of the extrapulmonary bronchus was rarely observed and represented by few diffusely distributed lymphocytes. Similar findings were recorded in cattle (Anderson et al. 1986). This indicated that the BALT of the extrapulmonary bronchus developed postnatally to reach its well-organized structure in the age of 3-4 years as described in children (Heier et al. 2011). This well-organized BALT continues for years as seen in this study till 7 years followed with involution which was prominent in 12 years camels as observed in cattle (Anderson et al. 1986). Therefore, the maximum immunological role of the BALT of the extrapulmonary bronchus in the camel may be at the age of 3-7 years. This should be considered in aerosol vaccination and immunological studies, where BALT is an entry site for antigens or vaccines which is essential for applying a successful mucosal vaccination through trachea (Pabst and Tschernig 2010). The well-organized BALT is characterized by secondary lymphoid nodules where the germinal center indicates the active role of BALT of the extrapulmonary bronchi in the immune reaction. In the present work, the 

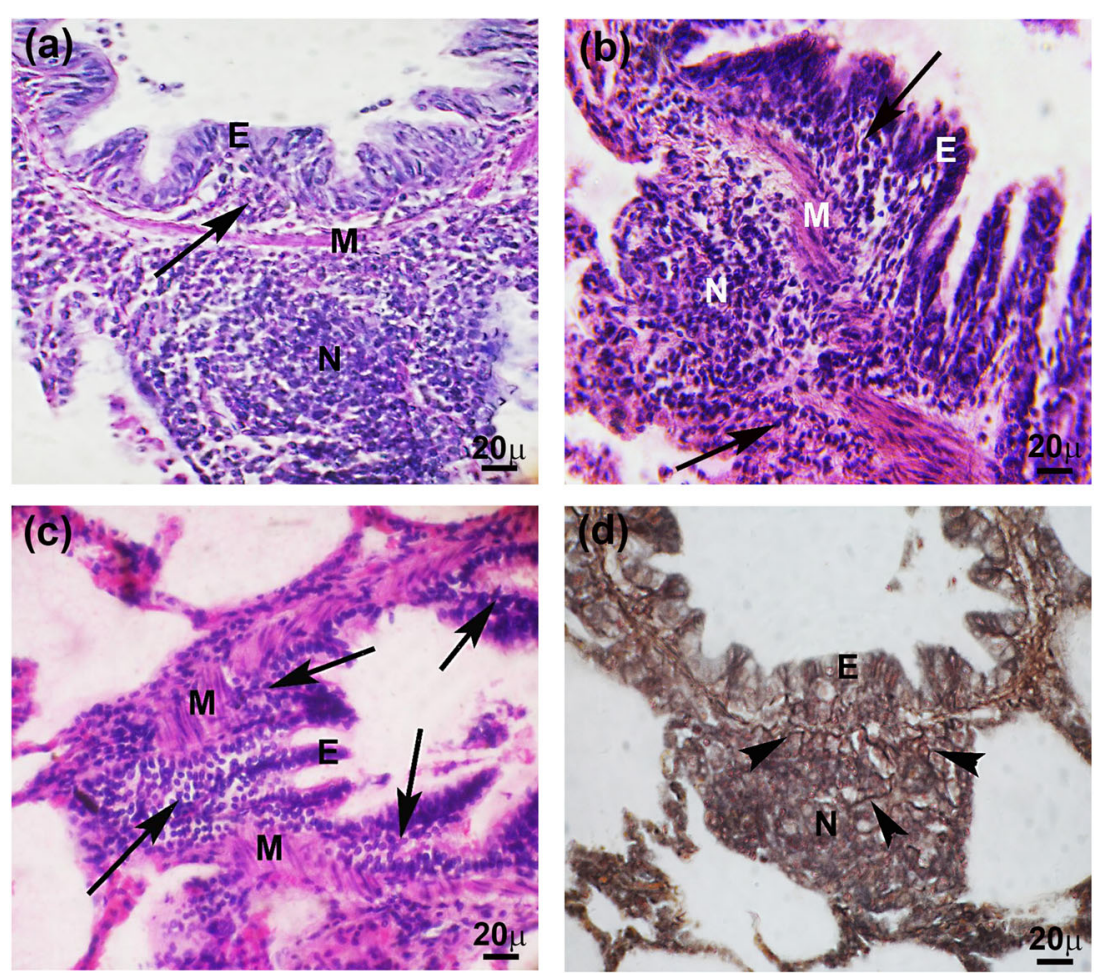

Fig. 4 Camel bronchioles. (a) The BALT at 10 years is formed of diffused lymphocytes (arrow) in the lamina propria and lymphoid nodule $(\mathrm{N})$ in the adventitia. The associated epithelium (E) is simple columnar without goblet cells or mucous secreting cells infiltrated with lymphocytes. M, smooth muscles. Alcian blue-PAS. (b) At 4 years, there is lymphoid nodule $(\mathrm{N})$ in the submucosa and diffused lymphocytes (arrows) in the lamina propria and submucosa. $M$, smooth muscles. $E$,

secondary lymphoid nodules of the BALT showed germinal center with dark corona facing the associated epithelium. Kumar and Timoney (2005) reported a similar lymphoid organization in equine palatine tonsils. The different forms of BALT of the camel were supported with reticular fiber framework. This reticular framework plays an essential role in lymphocyte homing (Tanaka et al. 1996; Satoh et al. 1997). In accordance with Aleksandersen et al. (1991), Alluwaimi et al. (1998), and Zidan and Pabst (2008), the BALT-associated epithelium was devoid of goblet cells as the follicle-associated epithelium of the Peyer's patches. The presence of high endothelial venules and lymphatic vessels was a constant structure of BALT of all ages, but it was prominent in the middle age associated with the prominent BALT to play their vital role as a rout of recirculation of lymphocytes as reported by Otsuki et al. (1989). In the intrapulmonary bronchus, the BALT was observed as a discontinuous subepithelial lymphoid aggregation through the wall of different bronchi (primary, secondary, and tertiary). The associated epithelium was formed from pseudostratified columnar ciliated acid mucin-secreting cells without goblet cells in general as observed in children bronchi (Heier et al. 2011). Neutral mucin-secreting cells increased gradually at the expense of acid mucin secreting cells with age.

associated epithelium. H\&E. (c) The BALT of 12 years camel is formed of diffused lymphocytes (arrows) in the lamina propria, interrupting the muscularis (M) also in the adventitia. The associated epithelium (E) is simple cuboidal epithelium. H\&E stain. (d) The BALT of 10 months camel is supported with reticular fibers (arrowheads) and has the lymphoid nodule $(\mathrm{N})$ and associated epithelium (E). Gordon and Sweet's reticulin

Ultrastructure of these mucous secreting cells showed that these cells produce the characteristic bipartite mucous secretory granules of low and high electron-dense parts. The ordinary low dense portion of the granule was predominating. This mucous was observed only in the gastric epithelium of European beaver (Castor fiber) (Ziolkowska et al. 2014) who described it as a unique morphological feature with possible general biological significance. More biochemical investigation may explain its role. The associated epithelium may be infiltrated by lymphocytes forming lymphoepithelium or even reticuloepithelium. The same was observed in human lung (Gould and Isaacson 1993). These finding differs from that of Chen et al. (1989) who found that the epithelium overlying the BALT in sheep was an ordinary, unspecialized epithelium and not considered a lymphoepithelium. The characteristics of lymphoepithelium and reticuloepithelium were also described in buffalo and camel palatine tonsils (Zidan and Pabst 2009, 2011). The presence of lymphoepithelium and reticuloepithelium may be due to antigen stimulation (Perry 1994; Zidan and Pabst 2011). As throughout this study, no specialized cells like $\mathrm{M}$ cell were observed; therefore, this lympho-epithelial barrier samples and translocates antigens to the underlying lymphoid tissue (Perry and Whyte 1998). 
This makes it very likely that the camel BALT plays a continuous role in immunity during the animal's life and encourages the aerosol vaccination programs. The subepithelial lymphoid structure was ranged from diffused lymphocytes to well-organized lymphoid nodules. Similar findings were observed in children (Heier et al. 2011). The BALT was well organized in the form of prominent lymphoid nodules with clear germinal centers and diffused lymphocytes in camels of 10 months -7 years old. In the older camel, no or few diffused lymphocytes were localized only in the lamina propria. The BALT was more prominent in the intrapulmonary bronchi than that of the extrapulmonary bronchi; this may be referred that the intrapulmonary bronchi is longer, with a narrow lumen and thinner epithelium that allow more contact with airborne antigen and facilitate antigen translocation to the associated lymphoid tissue. The development of several secondary lymphoid nodules in the BALT of the bronchi is explained by the exposure of the camel to unlimited number of antigens by inhalation from the surrounding environment. The presence of these secondary lymphoid nodules in the BALT indicates their role in lymphocyte and antibody production in a response to antigenic stimulation (Press and Landsverk 2006). This may also, as be mentioned before, indicate that aerosol vaccination could be applied in the camel to control and prevent airborne infectious diseases. The involution of the BALT in camels of 12 years old indicates that the BALT subjected to the ordinary age-related involution as a part of the immune system as BALT of cattle (Anderson et al. 1986) differs from the Peyer's patches of the camel which persist lifelong (Zidan and Pabst 2008). Although the size of BALT increased in adult and middle age group of camel studied, this could not be interpreted as an age-dependent development. Instead, repeated antigenic stimulation might cause such proliferation as was discussed on the goat (Barman et al. 1996). The BALT of the camel possesses high endothelial venules in the periphery. This arrangement was observed in the BALT of rat (Otsuki et al. 1989) and camel lymph nodes (Zidan and Pabst 2012). The high endothelial venules are specialized vessels that support active lymphocyte transmigration from peripheral blood to secondary lymphoid organs (Zidan et al. 2000c). Recirculating lymphocytes may migrate across the wall of these venules from the blood to the BALT similar to other lymphoid tissue (Gowans and Knight 1964; Anderson and Anderson 1976) and filtered again into the associated lymphatic vessels which were observed in the margin of all BALT of the camel. This mechanism of lymphocytes recirculation was described in several lymphoid structures (Williams et al. 1995). The bronchioles are the narrowest part of the bronchial tree with the thinnest wall (Mescher 2018). The BALT was a consistent structure in the different age groups in the present study. It showed variable structure and location in different animals and even in the same animals ranged from few diffused lymphocytes in the lamina propria to organized nodule associated with diffused lymphocytes in the propria, submucosa, and adventitia of the bronchioles. Rodriguez et al. (2001) concluded that peribronchiolar aggregation of lymphoid cells occurs as a response against antigen stimulation. This may explain the presence of BALT in variable shapes and location as induced tissue in a response to antigenic stimulation. The locally produced antibody may protect the respiratory epithelium from invading antigens. Therefore, the BALT of the bronchioles of the camel may be an induced structure which occurs as a response of antigenic stimulation. This explained the presence of BALT in association with the bronchioles in different ages. The associated epithelium was simple columnar ciliated to simple cuboidal epithelium with Clara cells. No goblet cells or mucous secreting cells were observed. The thin epithelial lining and the reduced mucous on the surface of the bronchioles may facilitate invasion of antigen to the bronchiolar wall leading to the development of an immune reaction. Repeated stimulation may lead to the development of stronger immune reaction (Barman et al. 1996) and development of lymphoid nodules. Few interepithelial lymphocytes were seen this may be an immune response of a previously induced BALT to translocate and sample the antigen through the lympho-epithelial barrier to the underlying lymphoid tissue to initiate an immune reaction (Perry and Whyte 1998). The absence of high endothelial and lymphatic vessels in the BALT of the bronchioles indicates that there is no lymphocytic recirculation and ensures that the BALT of bronchioles is induced due to an immune reaction. In a conclusion, The BALT in the camel was a variable from few lymphocytes to well-organized lymphatic tissue with a clear germinal center. The BALT of the bronchi is a constant lymphoid tissue which may be of the large size with clear germinal center due to repeated immune reaction and involutes with age. The BALT of the bronchioles is induced and develops mainly due to an immune reaction. Therefore, it showed clear morphological appearance and persists throughout the animal life.

Code availability Not applicable.

Author contribution Both authors contributed to all sections of this work.

Data availability Not applicable.

\section{Declarations}

Ethical approval This article does not contain any studies with animals performed by any of the authors.

Consent to participate Not applicable. 
Consent for publication Not applicable.

Conflict of interest The authors declare no competing interests.

\section{References}

Aleksandersen, M., Nicander, L., \& Landsverk, T. (1991). Ontogeny, distribution and structure of aggregated lymphoid follicles in the large intestine of sheep. Developmental \& Comparative Immunology, 15(4), 413-422.

Alluwaimi, A., El-Bab, M. F., Ahmed, A., \& Ali, A. (1998). Studies on the ileal lymphoid tissue (Peyer's patches) in camels, Najdi sheep and cattle. Journal of Camel Practice and Research, 5(1), 13-18.

Anderson, A. O., \& Anderson, N. D. (1976). Lymphocyte emigration from high endothelial venules in rat lymph nodes. Immunology, 31(5), 731-748.

Anderson, M. L., Moore, P. F., Hyde, D. M., \& Dungworth, D. L. (1986). Bronchus associated lymphoid tissue in the lungs of cattle: relationship to age. Research in Veterinary Science, 41(2), 211-220.

Bancroft, J. D., \& Layton, C. (2019). The hematoxylins and eosin. In S. K. Suvarna, C. Layton, \& J. D. Bancroft (Eds.), Bancroft's Theory and Practice of Histological Techniques (Eighth Edition ed., pp. 126-138).

Barman, N. N., Bhattacharyya, R., Upadhyaya, T. N., \& Baishya, G. (1996). Development of bronchus-associated lymphoid tissue in goats. Lung, 174(2), 127-131.

Bienenstock, J., \& Befus, D. (1984). Gut- and bronchus-associated lymphoid tissue. American Journal of Anatomy, 170(3), 437-445. doi: https://doi.org/10.1002/aja.1001700316

Bienenstock, J., \& McDermott, M. R. (2005). Bronchus- and nasalassociated lymphoid tissues. Immunological Reviews, 206, 22-31.

Chen, W., Alley, M. R., \& Manktelow, B. W. (1989). Respiratory tractassociated lymphoid tissue in conventionally raised sheep. Journal of Comparative Pathology, 101(3), 327-340.

Elhussieny, O., Zidan, M., Doughbag, A., Zaghloul, D., \& Roshdy, K. (2017). Organization of the Bronchial Associated Lymphoid Tissue (BALT) of The Dromedary Camel (Camelus Dromedarius). Alexandria Journal of Veterinary Sciences, 54(1), 101.

Fagerland, J. A., \& Arp, L. H. (1990). A morphologic study of bronchusassociated lymphoid tissue in turkeys. American Journal of Anatomy, 189(1), 24-34.

Fagerland, J. A., \& Arp, L. H. (1993). Structure and development of bronchus-associated lymphoid tissue in conventionally reared broiler chickens. Avian Diseases, 37(1), 10-18.

Gould, S. J., \& Isaacson, P. G. (1993). Bronchus-associated lymphoid tissue (BALT) in human fetal and infant lung. The Journal of pathology, 169(2), 229-234.

Gowans, J. L., \& Knight, E. (1964). The route of re-circulation of lymphocytes in the rat. Proceedings of the Royal Society of London. Series B. Biological Sciences, 159(975), 257-282.

He, W., Zhang, W., Cheng, C., Li, J., Wu, X., Li, M., ... Wang, W. (2019). The distributive and structural characteristics of bronchusassociated lymphoid tissue (BALT) in Bactrian camels (Camelus bactrianus). PeerJ, 7, e6571-e6571.

Heier, I., Malmström, K., Sajantila, A., Lohi, J., Mäkelä, M., \& Jahnsen, F. L. (2011). Characterisation of bronchus-associated lymphoid tissue and antigen-presenting cells in central airway mucosa of children. Thorax, 66(2), 151.

Holt, P. G., Strickland, D. H., Wikström, M. E., \& Jahnsen, F. L. (2008). Regulation of immunological homeostasis in the respiratory tract. Nature Reviews Immunology, 8(2), 142-152.
Hussen, J., \& Schuberth, H-J. (2021). Recent Advances in Camel Immunology Frontiers in Immunology. 11:614150. doi: https:// doi.org/10.3389/fimmu.2020.614150.

Kumar, P., \& Timoney, J. F. (2005). Histology, immunohistochemistry and ultrastructure of the equine palatine tonsil. Anatomia Histologia Embryologia, 34(3), 192-198.

Layton, C., \& Bancroft, J. D. (2019). Carbohydrates. In S. K. Suvarna, C. Layton, \& J. D. Bancroft (Eds.), Bancroft's Theory and Practice of Histological Techniques (Eighth Edition) (pp. 176-197).

Mackenzie, J. S., \& Smith, D. W. (2020). COVID-19: a novel zoonotic disease caused by a coronavirus from China: what we know and what we don't. Microbiology Australia, MA20013-MA20013.

Mescher, A. L. (2018). Respiratory System Junqueira's Basic Histology: text and atlas (Fifteenth Edition) (pp. 349-370): McGraw-Hill Education.

Moyron-Quiroz, J., Rangel-Moreno, J., Carragher, D. M., \& Randall, T. D. $(2007,2007 / /)$. The Function of Local Lymphoid Tissues in Pulmonary Immune Responses. Paper presented at the Crossroads between Innate and Adaptive Immunity, Boston, MA. PP 55-68.

Otsuki, Y., Ito, Y., \& Magari, S. (1989). Lymphocyte subpopulations in high endothelial venules and lymphatic capillaries of bronchusassociated lymphoid tissue (BALT) in the rat. American Journal of Anatomy, 184(2), 139-146.

Pabst, R., \& Gehrke, I. (1990). Is the bronchus-associated lymphoid tissue (BALT) an integral structure of the lung in normal mammals, including humans? American Journal of Respiratory Cell and Molecular Biology, 3(2), 131-135.

Pabst, R., \& Tschernig, T. (2010). Bronchus-associated lymphoid tissue: an entry site for antigens for successful mucosal vaccinations? American Journal of Respiratory Cell and Molecular Biology, 43(2), 137-141.

Perry, M. E. (1994). The specialised structure of crypt epithelium in the human palatine tonsil and its functional significance. Journal of Anatomy, 185 (Pt 1), 111-127.

Perry, M., \& Whyte, A. (1998). Immunology of the tonsils. Immunology Today, 19(9), 414-421.

Press, C., \& Landsverk, T. (2006). Immune System. In J. Eurell \& B. Frappier (Eds.), Dellmann's Textbook of Veterinary Histology (Six Edition) (pp. 134-152). USA, UK, Australia: Blackwell publishing.

Randall, T. D. (2010). Bronchus-associated lymphoid tissue (BALT) structure and function. Advances in Immunology, 107, 187-241.

Rodriguez, F., Fernandez, A., Oros, J., Ramirez, A., Luque, R., Ball, H., \& Sarradell, J. (2001). Changes in Lymphocyte Subsets in the Bronchus-associated Lymphoid Tissue of Goats Naturally Infected with Different Mycoplasma Species. Journal of Veterinary Medicine, Series B, 48(4), 259-266.

Satoh, T., Takeda, R., Oikawa, H., \& Satodate, R. (1997). Immunohistochemical and structural characteristics of the reticular framework of the white pulp and marginal zone in the human spleen. The Anatomical Record, 249(4), 486-494.

Tanaka, H., Hataba, Y., Saito, S., Fukushima, O., \& Miyasaka, M. (1996). Phenotypic Characteristics and Significance of Reticular Meshwork Surrounding Splenic White Pulp of Mice. Journal of Electron Microscopy, 45(5), 407-416.

Thornton, D. J., Rousseau, K., \& McGuckin, M. A. (2008). Structure and function of the polymeric mucins in airways mucus. Annual Review of Physiology, 70, 459-486.

Williams, P., Bannister, L., Berry, M., Collius, P., Dyson, M., Dussek, J., \& Ferguson, M. (1995). Gray's Anatomy (Thirty-Ninth Edition) (pp. 1431-1437).

Wolfe, D. (2019). 6 - Tissue processing. In S. K. Suvarna, C. Layton, \& J. D. Bancroft (Eds.), Bancroft's Theory and Practice of Histological Techniques (Eighth Edition) (pp. 73-83).

Woods, A. E., \& Stirling, J. W. (2019). 21 - Transmission electron microscopy. In S. K. Suvarna, C. Layton, \& J. D. Bancroft (Eds.), 
Bancroft's Theory and Practice of Histological Techniques (Eighth Edition) (pp. 434-475).

Zhou, J., Chu, H., Chan, J. F.-W., \& Yuen, K.-Y. (2015). Middle East respiratory syndrome coronavirus infection: virus-host cell interactions and implications on pathogenesis. Virology Journal, 12(1), 218.

Zhu, S., Zimmerman, D., \& Deem, S. L. (2019). A Review of Zoonotic Pathogens of Dromedary Camels. EcoHealth, 16, 356 -377.

Zidan, M., \& Pabst, R. (2002). Lymphocyte proliferation in lymphoid organs of the dromedary camel using the monoclonal antibody MIB-5 against the proliferation-associated nuclear epitope Ki-67. Anatomia Histologia Embryologia, 31(5), 286-289.

Zidan, M., \& Pabst, R. (2008). Unique microanatomy of ileal peyer's patches of the one humped camel (Camelus dromedarius) is not age-dependent. Anatomical Record (Hoboken), 291(8), 1023-1028.

Zidan, M., \& Pabst, R. (2009). The microanatomy of the palatine tonsils of the one-humped camel (Camelus dromedarius). Anatomical Record (Hoboken), 292(8), 1192-1197. doi:https://doi.org/10. 1002/ar.20948

Zidan, M., \& Pabst, R. (2011). The microanatomy of the palatine tonsils of the buffalo (Bos bubalus). Veterinary Immunology and Immunopathology, 139(2-4), 83-89.

Zidan, M., \& Pabst, R. (2012). Histological, histochemical and immunohistochemical study of the lymph nodes of the one humped camel
(Camelus dromedarius). Veterinary Immunology and Immunopathology, 145(1), 191-198.

Zidan, M., Jecker, P., \& Pabst, R. (2000a). Differences in lymphocyte subsets in the wall of high endothelial venules and the lymphatics of human palatine tonsils. Scandinavian Journal of Immunology, 51(4), 372-376.

Zidan, M., Kassem, A., Dougbag, A., Ghazzawi, E. E., El Aziz, M. A., \& Pabst, R. (2000b). The spleen of the one humped camel (Camelus dromedarius) has a unique histological structure. Journal of Anatomy, 196 ( Pt 3)(Pt 3), 425-432.

Zidan, M., Schuberth, H., \& Pabst, R. (2000c). Immunohistology of the splenic compartments of the one humped camel (Camelus dromedarius). Veterinary Immunology and Immunopathology, 74(1-2), 17-29.

Ziolkowska, N., Lewczuk, B., Petrynski, W., Palkowska, K., Prusik, M., Targonska, K., Przybylska-Gornowicz, B. (2014). Light and electron microscopy of the European beaver (Castor fiber) stomach reveal unique morphological features with possible general biological significance. PLoS One, 9(4), e94590.

Publisher's note Springer Nature remains neutral with regard to jurisdictional claims in published maps and institutional affiliations. 